DOI: 10.12731/2227-930X-2020-2-23-28

УДК 004.514

\title{
РАЗРАБОТКА УПРАВЛЯЮЩИХ КОНФИГУРАЦИЙ SCADА ДЛЯ СИСТЕМЫ ЖКХ
}

Лысанов Д.М., Еремина И.И., Иимурадова И.И.

Статья посвящается особенностям применения системь SCADA для создания конфигураџий дистанщионного управления разными промышленными приборами. Это оборудование работает в режиме реального времени, где по каждому установленному датчику видно, что происходит в текущий момент и позволяет быстро реагировать на нестандартные ситуации и осуществлять регулирование параметров приборов в отдельности и системы в целом.

Ключевые слова: система SCADA; контроллер; управляющая конфигурациия.

\section{DEVELOPMENT OF SCADA CONTROL CONFIGURATIONS FOR UTILITIES}

\section{Lysanov D.M., Eremina I.I., Ishmuradova I.I.}

The article is devoted to the peculiarities of SCADA system application for creation of configurations of remote control of different industrial devices. This equipment works in real time, where for each installed sensor you can see what is happening at the moment and allows to react quickly to non-standard situations and to adjust the parameters of the instruments separately and the system as a whole.

Keywords: SCADA system; controller; control configuration.

\section{Введение}

Для создания управляющей конфигурации используется программная среда SCADA, имеющая достаточно большой набор функций. С помощью интегрированного WEB сервера любой пользователь может применять тот функционал, который требуется для выполнения его работы. 
SCADA-система включает в себя следующие основные подсистемы [1]:

- Драйверы для осуществления ввода-вывода данных - обеспечивают связь системы SCADA с промышленными контроллерами.

- Система реального времени - служит для обработки данных с учетом определенного временного интервала, а также приоритетов.

- Человеко-машинный интерфейс - отображает характеристики выполнения производственного процесса и служит для его контроля.

- Система логического управления - позволяет выполнять написанные пользователями программы для управления оборудованием.

- База данных реального времени - служит для протоколирования и хранения всех параметров процесса.

- Система управления тревогами - позволяет выполнять автоматический контроль возникающих событий, определять их критичность для процесса.

- Генератор отчетов - используется для проектирования различных отчетов о событиях произошедших в системе.

- Внешние интерфейсы - драйверы обмена данными между элементами производственной системы и различными приложениями.

\section{Материалы и методы исследования}

Через программу возможно подключение одновременно от 1000 объектов управления, что является важным при управлении жилым фондом. Дальность связи блока в радиусе 5 км от главного компьютера, с которого передаются команды по регулированию. Для увеличения площади покрытия, можно использовать ретрансляторы сигнала, что позволит увеличить радиус покрытия.

Особенностью системы является то что, только необходим только один главной компьютер, с которого происходит распределение 
команд. Если есть доступ к компьютеру через сеть, то к нему можно подключиться с любого устройства и производить регулировку приборов и сбор информации.

В качестве примера автоматизации в системе жилищного хозяйства приводится разработка системы управления задвижками в тепловом пункте. Каждая задвижка оснащается электроприводом и подключается к общему реле управления. Для обнаружения утечек устанавливаются датчики давления до и после задвижек, а также температурные датчики для контроля температурного режима. В системе индикация работы задвижки отражается информация в режиме реального времени о ее состоянии. Реле управления работает в двух режимах - закрыто и открыто. Система работает в двух режимах, автоматической регулировки, по заранее разработанному алгоритму и ручному дистанционному управлению.

\section{Результаты исследования}

На рисунке 1 представлены разработанные управляющие конфигурации для автоматического и ручного управления задвижкой, показаны данные информационной системы управления оборудованием [2].
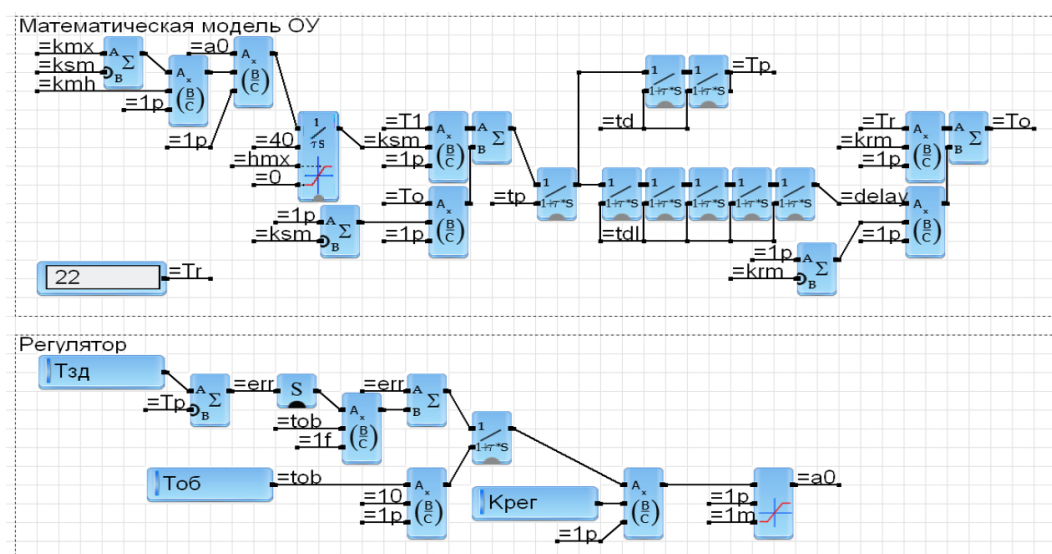

Рис 1. Управляющие конфигурации для задвижки

$\mathrm{kmx}$ - информация давления манометра перед задвижкой.

ksm - информация температурного режима перед задвижкой. 
$\mathrm{kmh}$ - индикация рабочего состояния задвижки.

$1 \mathrm{p}$ - передача информации на пульт управления по давлению.

$\mathrm{a} 0$ - регулировка степени открытия задвижки в зависимости от давления.

$\mathrm{hmx}$ - минимально допустимая температура на обратном трубопроводе.

T1 - Температура подачи горячей воды, отопления в доме.

Т0 - Температура подачи энергоресурса в трассе.

tp - регулирование по стандартной программе.

td - передача данных на модуль контроля работы программы.

$\mathrm{Tp}$ - учет расхода потребляемой энергии.

$\mathrm{krm}$ - сбор данных по ошибкам в работе.

$\operatorname{Tr}$ - количество подключенных модулей к одной панели управления.

Математическая модель применяется для создания команд взаимосвязи между модулем управления, реле управления и датчиками давления и температуры, а также индикации их функционирования. Регулятор используется для автоматического и ручного управления системой по заданным заранее параметрам, а также передачи данных на управляющий модуль.

\section{Обсуждение}

На рисунке 2 представлена схема автоматизированного теплового пункта.

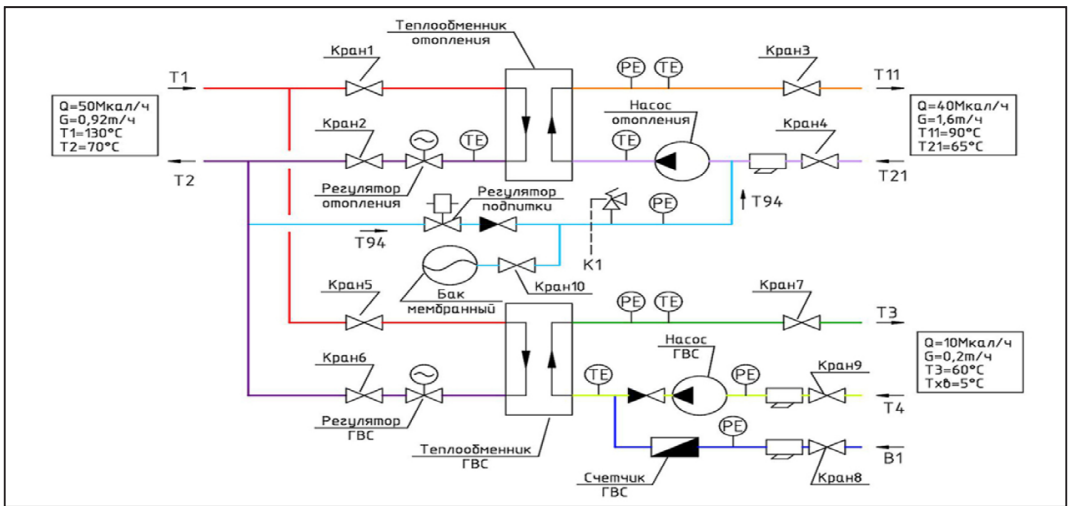

Рис. 2. Схема автоматизированного теплового пункта

$\mathrm{Q}$ - максимальный полезный рабочий объем теплообменника.

$\mathrm{G}$ - пропускная способность в тонн/час.

$\mathrm{T} 1$ - максимальная температурная нагрузка.

Т2 - максимальная отопительная нагрузка. 
Задвижки оснащены электроприводом для дистанционного открытия и закрытия. Информация с приборов учета считывается и постоянно передается на главной компьютер в офисе с помощью GSM модуля. Также возможно дистанционное переключение режимов работы насосов и их полная остановка при необходимости отключения системы водоснабжения.

\section{Заключение}

В реле управления загружаются разработанные стандартные конфигурации различного оборудования с учетом назначения. Устанавливается радиопередатчик, который организует канал связи и осуществляет постоянное взаимодействие через сеть с главным компьютером. К управляющему реле присоединяются импульсные счетчики, которые передают данные о расходе энергоресурсов.

\section{Список литературы}

1. Елизаров И.А. Интегрированные системы проектирования и управления: SCADA-системы. Тамбов: ФГБОУ ВПО «ТГТУ», 2015.

2. Lysanov D.M., Isavnin A.G., Eremina I.I., Ishmuradova I.I., Karamyshev A.N. System Design of Management of Energy Resources in the Field of Housing // HELIX. 2019. Vol. 9. Is. 4.

\section{References}

1. Elizarov I.A. Integrirovannye sistemy proektirovaniya i upravleniya: SCADA-sistemy [Integrated design and control systems: SCADA systems]. Tambov: FGBOU VPO «TGTU», 2015.

2. Lysanov D.M., Isavnin A.G., Eremina I.I., Ishmuradova I.I., Karamyshev A.N. System Design of Management of Energy Resources in the Field of Housing. HELIX. 2019. Vol. 9. Is. 4.

\section{ДАННЫЕ ОБ АВТОРАХ}

Лысанов Денис Михайлович, кандидат технических наук, доцент Набережночелнинский институт ФГАОУ ВО «Казанский федеральный университет»

пр-m Сююмбике, 10a, г. Набережные Челны, 423812, РФ kampi_ldm@mail.ru 
Еремина Ирина Ильинична, кандидат педагогических наук, доцент Набережночелнинский институт ФГАОУ ВО «Казанский федеральный университет»

пр-т Сююмбике, 10а, г. Набережные Челны, 423812, РФ ereminaii@yandex.ru

Ишмурадова Изида Илдаровна, кандидат экономических наук, доцент

Набережночелнинский институт ФГАОУ ВО «Казанский федеральный университет»

nр-т Сююмбике, 10a, г. Набережные Челны, 423812, РФ IIIshmuradova@kpfu.ru

\section{DATA ABOUT THE AUTHORS}

Lysanov Denis Mihailovich, Associate Professor, Ph.D. in Technical Sciences

Naberezhnye Chelny Institute of Kazan Federal University

Syuyumbike Ave., 10a, Naberezhnye Chelny, 423812, Russian Federation

kampi_ldm@mail.ru

ORCID̄: 0000-0002-0728-4435

Eremina Irina Ilinichna, Associate Professor, Ph.D. in Education Naberezhnye Chelny Institute of Kazan Federal University Syuyumbike Ave., 10a, Naberezhnye Chelny, 423812, Russian Federation ereminaii@yandex.ru

ORCID: 0000-0003-2333-3935

Ishmuradova Izida Ildarovna, Associate Professor, Ph.D. in Economics Naberezhnye Chelny Institute of Kazan Federal University Syuyumbike Ave., 10a, Naberezhnye Chelny, 423812, Russian Federation

IIIshmuradova@kpfu.ru

ORCID: 0000-0001-6307-8292 